\title{
Rheological Investigation of Self-emulsification Process
}

\author{
Shailesh V. Biradar, Ravindra S. Dhumal, Anant Paradkar*
}

Department of Pharmaceutics, Bharati Vidyapeeth University, Poona College of Pharmacy, Erandwane, Pune 411038 , Maharashtra State, India

Received August 10, 2008; Revised January 17, 2009; Accepted January 13, 2009, Published February 8, 2009.

\begin{abstract}
Purpose. Aim of the study is to explore the viscoelastic properties of intermediate liquid crystalline (LC) phase formed during self-emulsification and to evaluate its influence on self-emulsification performance. Methods. Binary system of tween 80 (T80) and imwitor 742 (I742) was used and different SES were prepared with I742 at 10, 30, 50, 70 and $90 \% \mathrm{w} / \mathrm{w}$ concentration levels. Self-emulsification was monitored by visual observations and droplet size measurement. Mesophases obtained by $50 \% \mathrm{v} / \mathrm{v}$ aqueous hydration of SES were utilized for polarizing microscopy, differential scanning calorimetry and rheological studies. Results. SES 30\% presented good emulsifying properties and nano-size droplets were observed after its emulsification as compared to micron sized droplets for other SES. In polarizing microscopy, formation of intermediate LC phase was observed in all SES. Lamellar phase was evident in 30\% SES while other SES exhibited micellar cubic phase. Presence of high level of structurally bound water in thermal analysis confirmed mesophase formation in all SES. In frequency sweep, decrease in elastic modulus, an increase in phase degree and loss tangent was observed for 30\% SES. Exactly opposite trend was seen in other SES. Thus, rheological studies concluded presence of weak and fragile mesophase structure in 30\% SES while LC phase structure with little structural buildup was observed in other SES. This weak mesophase structure in SES 30\% presented no or very little resistance against strain induced deformation. Therefore, during emulsification, weak mesophase in SES 30\% ruptured with ease and released jet of nano-size droplets compared to coarse droplets for other SES. Conclusion. This study signifies the effect of viscoelastic properties of intermediate LC phase on selfemulsification performance.
\end{abstract}

\section{INTRODUCTION}

Self-emulsifying drug delivery system (SEDDS) is a mixture of oil and surfactant, which emulsify under gentle condition of agitation. Use of SEDDS for enhancement of oral bioavailability of hydrophobic drugs has recently gained much interest $(1,2)$. Self-emulsification performance is evaluated on the basis of achieved droplet size; generally lower droplet size indicates better performance. The self-emulsification ability of selfemulsifying system (SES) is attributed to type of oil and surfactant (3). Although plenty of work has been carried out on design, optimization and use of self-emulsifying system, factors determining the self-emulsification ability of particular oil and surfactant ratio are still subject of speculation. Researchers have concluded that SES performance depends on formulation related parameters, such as surfactant concentration, oil/surfactant ratio, polarity of the emulsion, droplet size and charge (4). Reiss et al. (5) suggested that self- emulsification takes place when the entropy change favoring dispersion is greater than the energy required to increase the surface area of the dispersion. Also for a system to undergo selfemulsification, there should be no resistance against surface shearing and the free energy requirement should be low $(6,7)$.

Work by Groves and Galindez (8) proved the formation of intermediate liquid crystalline (LC) phase in SES between the oil/surfactant and water phase, which swells, thereby allowing spontaneous formation of an interface between the oil droplets and water.

Correspondence Author: Prof. A. R. Paradkar, Dept. of Pharmaceutics, Bharati Vidyapeeth University, Poona College of Pharmacy, Erandwane, Pune 411 038, Maharashtra State, India E-mail- arparadkar@rediffmail.com 
Pouton (9) attributed self-emulsification to LC phase formation, oil-water phase-inversion temperature and enhanced solublization of water by oily formulations. Pouton (10) further pointed that the formation of LC phase at interface may depend on the proportion of oil, surfactant and water present. The characteristic of LC phase formed at oil/water interface was investigated extensively using polarizing light microscopy by Rang et al. (11) and Wakerly et al. (12). It was suggested that the rate of emulsification is related to rate and extent of water penetration into the LC or gel phases formed on the surface of the droplet. This is followed by the solublization of water within the oil phase. The process will continue until the solubilization limit is reached close to the interface. Further aqueous penetration will lead to the formation of dispersed LC phase. Thus, on gentle agitation of the SES, water will rapidly penetrate and lead to interface disruption and droplet formation. Craig et al. (13) explored the selfemulsification performance of SES based on binary mixture of $\mathrm{I} 742$ and T80 by droplet size measurement and dielectric spectroscopy. LC phase formation in some SES was confirmed by low frequency dielectric spectroscopy and was correlated with the performance of selfemulsification. This work though provided the significance of intermediate LC phase, a strong relationship between LC phase and performance parameters was not established.

At present there are different schools of thoughts to explain the mechanism of selfemulsification. In spite of various attempts, the process is still not clearly elucidated. Therefore, additional experimental work is required to unveil the mechanism of self-emulsification. Interestingly, few researchers have proved that self-emulsification process proceed through LC phase formation and its subsequent rupture. However, the correlation between self-emulsification performance and properties of LC phase is still not established. Hence, it will be pivotal to study the structural and physical properties of intermediate LC phase. As rupture of intermediate LC phase is now being noticed as a key step in self-emulsification process, viscoelastic properties of LC phase must be influencing the pattern of LC phase rupture, which subsequently governs the observed droplet size. Therefore, it will be logical to explore the viscoelastic properties of intermediate LC phase by rheological analysis to evaluate its effect on selfemulsification performance. As self-emulsification process is very rapid and spontaneous, it is not possible to study the intermediate LC phase with normal set of condition. Therefore, arresting this process at a critical stage will be more advantageous. Hence, in this study, SES were subjected to controlled hydration and the viscoelastic properties of intermediate LC phase just prior to emulsification were analyzed using rheological tool. The relationship between viscoelastic properties of LC phase and selfemulsification performance is explored in depth.

\section{MATERIALS AND METHODS}

\section{Materials}

Imwitor $742^{\circledR}$ (I742, blend of mono, di- and triglycerides, chiefly caprylic $\left[\mathrm{C}_{8} \mathrm{H}_{16} \mathrm{O}_{2}\right]$ and capric acid $\left.\left[\mathrm{C}_{10} \mathrm{H}_{20} \mathrm{O}_{2}\right]\right)$ was a generous gift from Sasol GmbH, Germany. Tween 80 (T80: Polyoxyethylene 20 sorbitan monooloeate) was purchased from Merck Chemicals, Mumbai, India. Distilled water was used for hydration of SES.

\section{Formulation of SES}

Initially, I742 was heated at $45{ }^{\circ} \mathrm{C}$ for $30 \mathrm{~min}$ and then cooled to room temperature. Five different SES were prepared by mixing I742 at $10,30,50$, 70 and $90 \%$ w/w concentration levels with corresponding concentration of T80 (Table 1). Prepared SES (unhydrated) were used for visual inspection and droplet size measurement.

\section{Hydration of SES}

The prepared SES were hydrated at 10, 30, 50 and $70 \% \mathrm{v} / \mathrm{v}$ hydration levels with respect to oil: surfactant mixture by using distilled water and mixed manually. Prepared hydrated SES were stored for $24 \mathrm{~h}$. SES with optimum hydration were used for other measurements in this study.

\section{EVALUATION OF SES}

\section{Emulsifying properties}

Emulsifying properties were visually observed as per Collaborative International Pesticide Analytical 
Council (CIPAC) test (14). A fixed amount $(0.6 \mathrm{ml})$ of SES were added to $400 \mathrm{ml}$ distilled water at $25^{\circ} \mathrm{C}$ and performance of spontaneous emulsification was observed visually and analyzed according to droplet formation pattern. This test was performed in triplicate.

\section{Droplet size measurement}

Droplet size was measured by Laser Diffractometer (LD) Mastersizer 2000 Ver. 2.00 (Malvern Instruments, Malvern, UK). The data was presented in terms of median $\left(\mathrm{D}_{50}\right)$ volume and the span, which were calculated by Malvern Software Ver 3.0. For measurement, SES were pre-diluted by addition of $1 \mathrm{ml}$ of SES to $10 \mathrm{ml}$ of distilled water under slow agitation at room temperature $\left(25^{\circ} \mathrm{C}\right)$. The system was analyzed by dispersing it in $100 \mathrm{ml}$ distilled water as dispersant. Analysis was done in triplicate.

\section{Polarizing light microscopy}

Hydrated SES were transferred to a specially fabricated glass tube (internal diameter $0.5 \mathrm{~cm}$ ) and then viewed for presence or absence of birefringence under polarizing microscope at $25^{\circ} \mathrm{C}$ with $\lambda 1 / 4$ compensator (Nikkon Eclipse E 600, Nikon Instech Co., Japan).

\section{Differential scanning calorimetry (DSC)}

DSC measurements were performed with Mettler Toledo 821e instruments equipped with an intracooler (Mettler Toledo, Switzerland). A $10 \pm 3$ $\mathrm{mg}$ of hydrated SES sample was placed in closed aluminum crucibles and cooled to $-20^{\circ} \mathrm{C}$ at the rate of $10{ }^{\circ} \mathrm{C} / \mathrm{min}$. It was maintained at $-20{ }^{\circ} \mathrm{C}$ for 10 min. and then subjected to heating from -20 to 100 ${ }^{\circ} \mathrm{C}$ at the scanning rate of $5{ }^{\circ} \mathrm{C} / \mathrm{min}$. Calibration was performed with Indium/zinc at same scanning rate.

\section{Rheological studies}

Rheological measurements of hydrated SES were performed using a controlled stress rheometer (Viscotech Rheometer, Rheologica Instruments AB, Lund, Sweden). Data analysis was done with Stress RheoLogic Basic software, version 5.0. A cone and plate geometry was used with $25 \mathrm{~mm}$ diameter and cone of $1.0^{\circ}$. Fresh sample was used for every test and all measurements were carried out at $25^{\circ} \mathrm{C}$. All tests were carried out in triplicate.

Viscometry: The samples were exposed to increasing stress (0.1-100 $\mathrm{Pa}$ ) and relation between shear stress and shear rate was studied.

Oscillation stress sweep: Linear viscoelastic region (LVR) was determined in the stress range of $0.1-100 \mathrm{~Pa}$ at a constant frequency $(1 \mathrm{~Hz})$. The ability of hydrated SES to resist the deformation with applied stress was recorded in terms of trends of elastic modulus $\left(G^{\prime}\right)$ and loss modulus (G').

Oscillation frequency sweep: The samples were exposed to increasing frequency (0.1$10 \mathrm{~Hz}$ ) at a constant stress in LVR. Effect of frequency on $\mathrm{G}^{\prime}, \mathrm{G}^{\prime \prime}$, phase degree $(\delta)$ and loss tangent $(\tan \delta)$ were recorded.

Creep-recovery: SES samples were exposed to a constant stress in LVR for 100 s. It was then instantly removed and the recovery was followed for 200s. The creep compliance, $\mathrm{J}$ (defined as ratio between measured strain and applied stress) was recorded against time.

\section{RESULTS}

\section{Emulsifying properties}

Spontaneous and good emulsification was observed for 30, 50 and 70\% SES. SES with higher amounts of T80 (10\% SES) had shown formation of large droplets at the bottom while SES with higher I742 (90\% SES) has shown formation of oily layer on surface of water. Hence, these SES have shown moderate to poor self-emulsifying properties (Table $1)$.

\section{Droplet size measurement}

Droplet size decreased with increase in $\mathbf{I 7 4 2}$ concentration up to $30 \%$ SES and later increased with an increase in 1742 concentration (Table 2). The droplet size was in nano range for $30 \%$ SES, whereas it was in micron range for other SES. Therefore, efficient self-emulsification was observed for SES 30\% as compared to other SES. 
Table 1. Visual assessment of emulsification process of studied SES ( $n=3)$

\begin{tabular}{lll}
\hline $\begin{array}{l}\text { Composition } \\
\mathbf{( \%} \mathbf{~ w / w ~ I 7 2 )}\end{array}$ & $\begin{array}{l}\text { Ease of } \\
\text { emulsification }\end{array}$ & Observations \\
\hline 10 & poor & $\begin{array}{l}\text { No emulsification. Large droplets were observed at bottom of } \\
\text { beaker }\end{array}$ \\
& Spontaneous emulsification was observed with jet of droplet \\
& spreading thoroughly in beaker \\
30 & good & Spontaneous emulsification as 30\% system \\
50 & good & good emulsification was observed \\
70 & Layer of oil droplet was formed, get emulsified on gentle \\
90 & stirring \\
\hline
\end{tabular}

Table 2. Droplet size of studied SES

\begin{tabular}{lll}
\hline SES \% & $\begin{array}{l}\text { Droplet size } \\
\mathbf{( D}_{\mathbf{5 0}} \mathbf{)} \boldsymbol{\mu m}\end{array}$ & Span $^{\mathbf{a}, \mathbf{b}}$ \\
\hline 10 & $88.21 \pm 2.070$ & $3.64 \pm 0.045$ \\
30 & $0.187 \pm 0.002$ & $5.38 \pm 0.053$ \\
50 & $6.597 \pm 0.136$ & $3.43 \pm 0.067$ \\
70 & $10.10 \pm 0.191$ & $2.17 \pm 0.037$ \\
90 & $8.28 \pm 0.158$ & $5.38 \pm 0.071$ \\
\hline
\end{tabular}

a mean \pm S.D. $(n=3)$

b $\mathrm{Span}=\mathrm{d}(0.9)-\mathrm{d}(0.1) / \mathrm{d}(0.5)$

\section{Polarizing light microscopy}

SES were hydrated at different levels in order to check the formation of LC phase. The characterization of the LC phase formed after hydration of SES was done under polarizing light microscope and according to the classification established by Rosevear (15) and Ivanova et al. (16), where dark, mosaic planer anisotropic and fan like anisotropic texture is reported for cubic, lamellar and hexagonal phase, respectively. From visual observation and polarizing microscopic studies, the $50 \% \mathrm{v} / \mathrm{v}$ hydration was kept constant for further studies as at lower hydration levels, LC phase formation was not observed in all SES, while at higher hydration levels, emulsification was observed in some SES.

Observed LC phases in the hydrated SES $(50 \% \mathrm{v} / \mathrm{v})$ are shown in Figure 1. Presence of birefringence was observed for $30 \%$ SES while dark texture was seen for 10, 50, 70 and $90 \%$ SES. Thus, lamellar phase formation was confirmed in $30 \%$ SES while micellar cubic phase was evident in 10, 50, 70 and 90\% SES. Micellar cubic phase was identified on the basis of liquid like consistency and observed isotropic texture of formed LC phase (1719). 


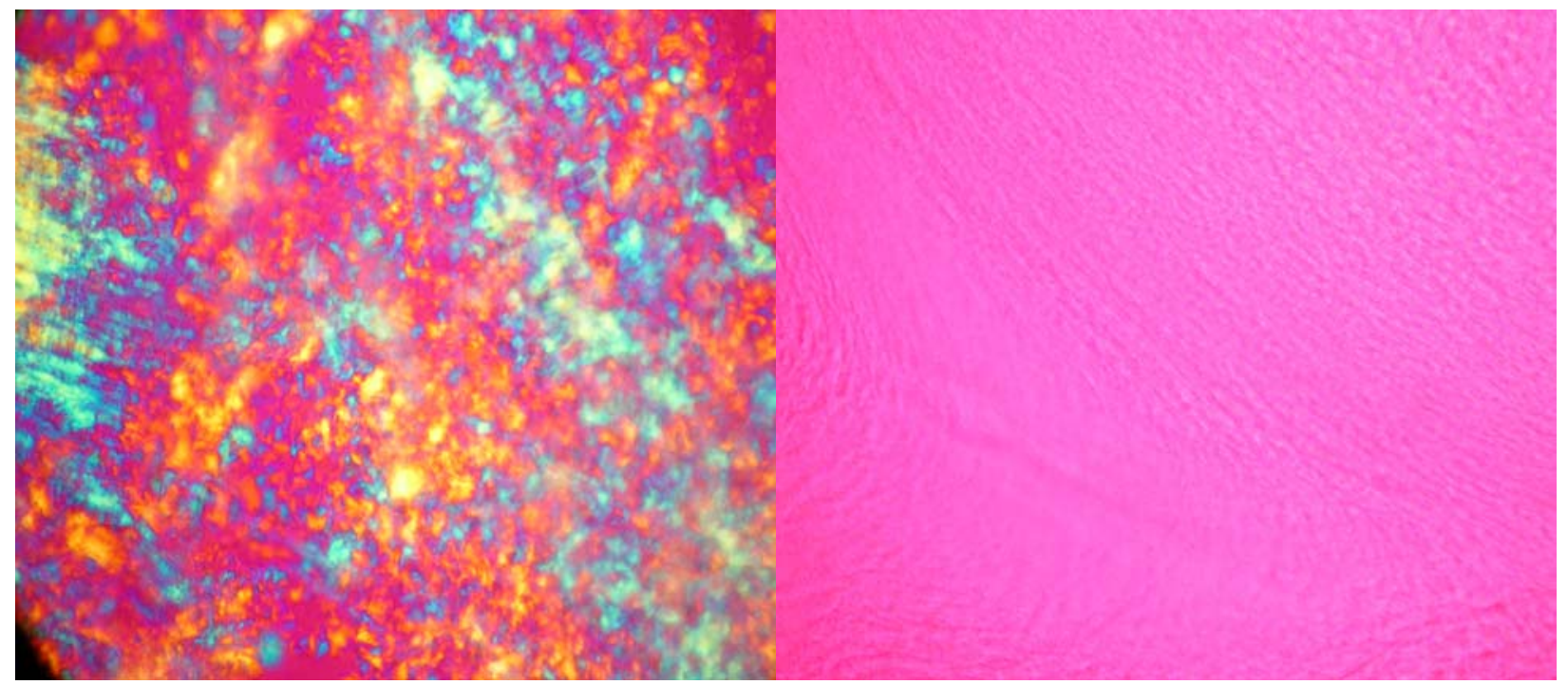

A

$\mathrm{B}$

Figure 1. Photographs of different LC phase observed under polarizing light microscope in studied SES: ALamellar phase; B- Micellar cubic phase.

\section{Differential scanning calorimetry (DSC)}

Garti et al. (20) reported presence of bound and free water in surfactant based systems with LC phase formation. Bound water, which is consumed for the formation of LC phase, has different thermal properties as compared to free or unbound water. Free water does not associate with surfactant and has properties same as that of pure water. During DSC studies of such system, peak corresponding to melting of freezed unbound water appears close to $0^{\circ} \mathrm{C}(20-21)$. Thermograms of SES were studied for presence of an endothermic peak corresponding to free water close to $0^{\circ} \mathrm{C}$ (Figure 2).

In heating cycle, hydrated SES with higher I742 concentrations (50, 70, and 90\% SES) presented an endothermic peak close to $0{ }^{\circ} \mathrm{C}$. The observed peak in 50, 70, and 90\% SES was absent in DSC thermograms of unhydrated 10, 30, 50, 70, and 90\% SES and plain I742 and T80 (Data not shown). Therefore, this peak was attributed to the melting of free water as similar that peak was observed for pure water (Figure 2: DW). This peak for melting of free water was absent in the thermogram of 10 and $30 \%$ SES. Hence, it was concluded that free water was completely utilized for formation of LC phase in these SES owing to higher surfactant concentration while it was partially consumed in 50, 70 and $90 \%$ SES.

\section{Rheological studies}

Rheological analysis of hydrated SES was performed to investigate viscoelastic properties of LC phases formed after $50 \% \mathrm{v} / \mathrm{v}$ hydration. Measurements were performed by steady- state flow (rotational) and dynamic (oscillatory) measurement modes. The rheological data of only 10,30 and $50 \%$ SES is reported in figures as $70 \%$ and $90 \%$ SES followed the same trend as that of $50 \%$ SES.

\section{Viscometry}

The shear rate and shear stress profiles of the studied LC phases are shown in Figure 3. In SES $30 \%$, non-Newtonian relationship was observed between shear stress and shear rate while direct relationship was seen in other SES.

\section{Oscillation stress sweep}

Stress sweep was carried out to determine the LVR, where G' is independent of applied stress. Subsequent frequency sweep has to be carried out at constant stress in LVR presenting rheological ground state of material. The change in G' and G', over applied stress has been shown in Figure 4. SES $30 \%$ had shown rapid decrease in G' with applied 
stress while other SES have shown stable trends of G' and G', over entire stress range. As LVR of 10, 50,70 and $90 \%$ SES was different from that of SES $30 \%$, stress selected for subsequent frequency sweep was also different. In frequency sweep, applied stress for 10, 50, 70 and $90 \%$ SES was 20 $\mathrm{Pa}$ and for SES 30\%, it was $1.5 \mathrm{~Pa}$.

\section{Oscillation frequency sweep G' and G',}

Trend of G' and G', over applied frequency for LC phases of studied SES have been depicted in Figure 5. Both G' and G' were found to be function of applied frequency for all SES. In SES 30\%, G' was greater than G" at lower frequency and with an increase in frequency, G' was decreased while G', was increased and finally $G$ ' ' much greater than G'. For all SES, G' has increased significantly with frequency, whereas G', increased slowly and steadily and at end G' was dominating over G',

\section{Phase degree (ס)}

Phase degree $(\delta)$ is a good indicator of viscoelastic nature of system, being measure of the lag in sine response after an oscillatory frequency has been applied to the sample. For perfectly elastic system, $\delta$ is close to $0^{\circ}$ and perfect viscous system has $\delta$ close to $90^{\circ}$. The $\delta \geq 45^{\circ}$ indicates viscous nature of system while $\delta \leq 45^{\circ}$, represents elastic nature (22). The LC phases of all SES other than $30 \%$ exhibited higher phase degree i.e. viscous behavior at lower frequency, which decreased with frequency to end in the elastic region (Figure 6). The low $\delta$ values for LC phase of $30 \%$ SES indicate its elastic nature at lower frequency which increased with frequency tending the system towards viscous nature.

\section{Loss tangent (tan $\delta)$}

The loss tangent is a dimensionless parameter, which is ratio of G' to G'. Korohen (23) has shown that the system with $\tan \delta<1$ has predominantly elastic behavior and system with $\tan \delta>1$ has a prevailing viscous behavior. For SES 30\%, loss tangent was increased with applied frequency confirming transformation to viscous region while it was rather decreased below one for all other SES, indicating induction of an elastic region (Figure 7).

\section{Creep recovery}

The ability of material or system to regain original structure partially or fully after removal of stress is judged from presence instantaneous elastic recovery and viscoelastic recovery component in creep recovery. Perfectly elastic material or system presents both these components $(23,24)$. However, neither instantaneous elastic nor viscoelastic recovery was observed for any of the studied LC phases of SES (Figure 8). Thus, dependence of G' and $G$ ' over applied frequency and absence of recovery component in creep recovery justified selfemulsification ability of almost all SES as a recovering system will oppose the breakup or rupture or will not emulsify by virtue of its structure retaining ability.

\section{DISCUSSION}

In this study, self-nanoemulsification was observed for $30 \%$ SES while self-microemulsification was seen in other SES. Thus, it was observed that particular ratio of $\mathrm{I} 742$ and $\mathrm{T} 80$ produced nano droplets on self-emulsification while all other ratio produced micron sized droplets. Trend for droplet measurement in this study was matching with previous reports by Craig et al. (13), though there was numerical difference. This may be due to different dilutions followed for droplet measurement. Lower dispersant holding capacity of dispersion unit used of our analyzer restricted the use of higher dilutions used by Craig et al (13) (0.5 $\mathrm{ml}$ SES in $1 \mathrm{~L}$ of distilled water) as with higher dilutions, required obscuration was not achieved, especially for 10 and $20 \%$ SES. Therefore, modified method with lower dilution was adopted for droplet size measurement.

Among different hydration levels, $50 \% \mathrm{v} / \mathrm{v}$ level was selected for rheological investigation as it represents the phase just prior to emulsification. Phase characterization by texture analysis of hydrated SES under polarizing light microscopy was done in a glass tube because with conventional film technique, correct visualization of the LC phase formed in SES was not possible as suggested by Lawrenes and Rees (4). Though formation of LC phase was observed in polarizing microscopy, extent of LC phase formation was not concluded. The extent of LC phase formation can be determined by calculating the structurally bound 
water (SBW). SBW is directly related to the extent of LC phase formation; higher the SBW, higher is extent. Normalized melting enthalpies for free water in SES thermograms were used for calculating SBW by following formula (25).

$\mathrm{SBW}=\left[1-\left(\mathrm{H}_{1} / \mathrm{H}_{\mathrm{o}}\right)\right] \times 100$

Where,

$\mathrm{H} 1$ = melting enthalpy of water determined from the sample
Ho = standard melting enthalpy of water $(-333.6$ $\mathrm{J} / \mathrm{g})$.

It was observed that the extent of LC phase formation decreased with an increase in $I 742$ concentration and more than $70 \%$ of LC phase formation was seen in all SES (Table 3).

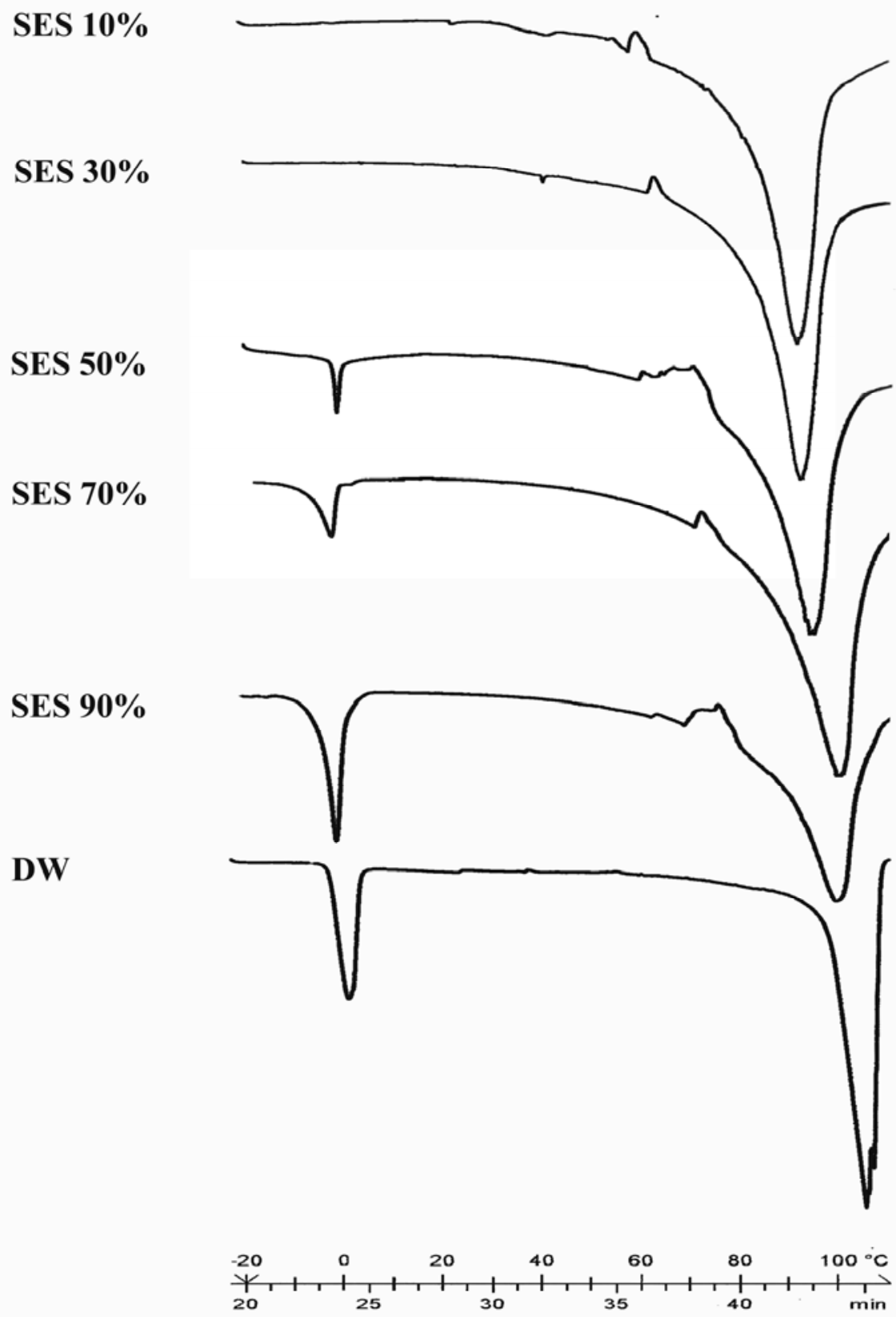

Figure 2. DSC thermograms of studied SES 


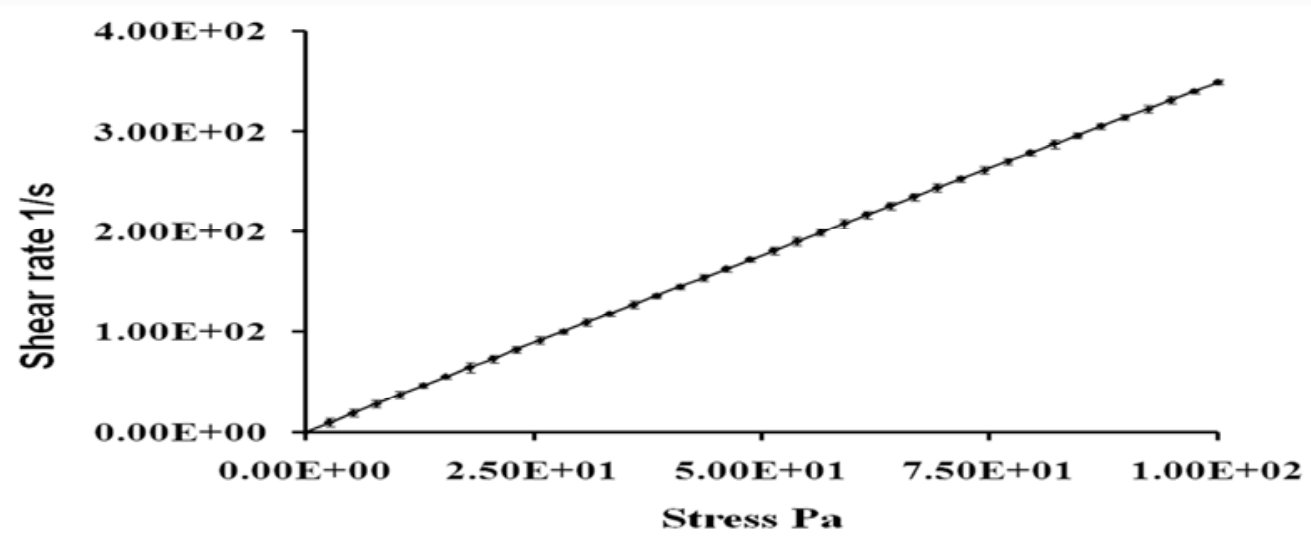

A

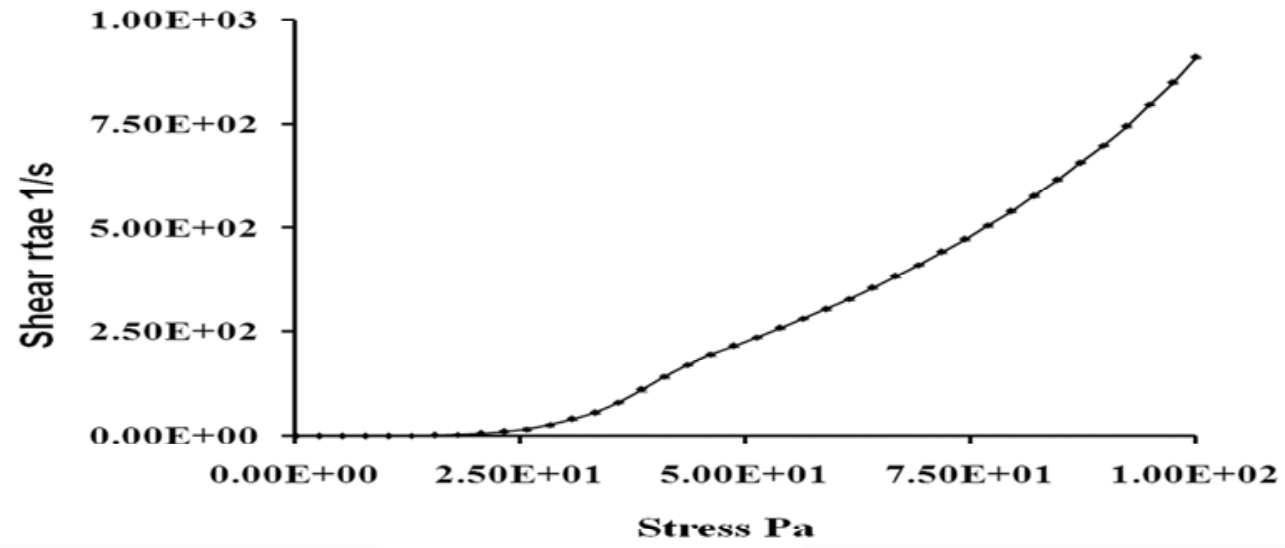

B

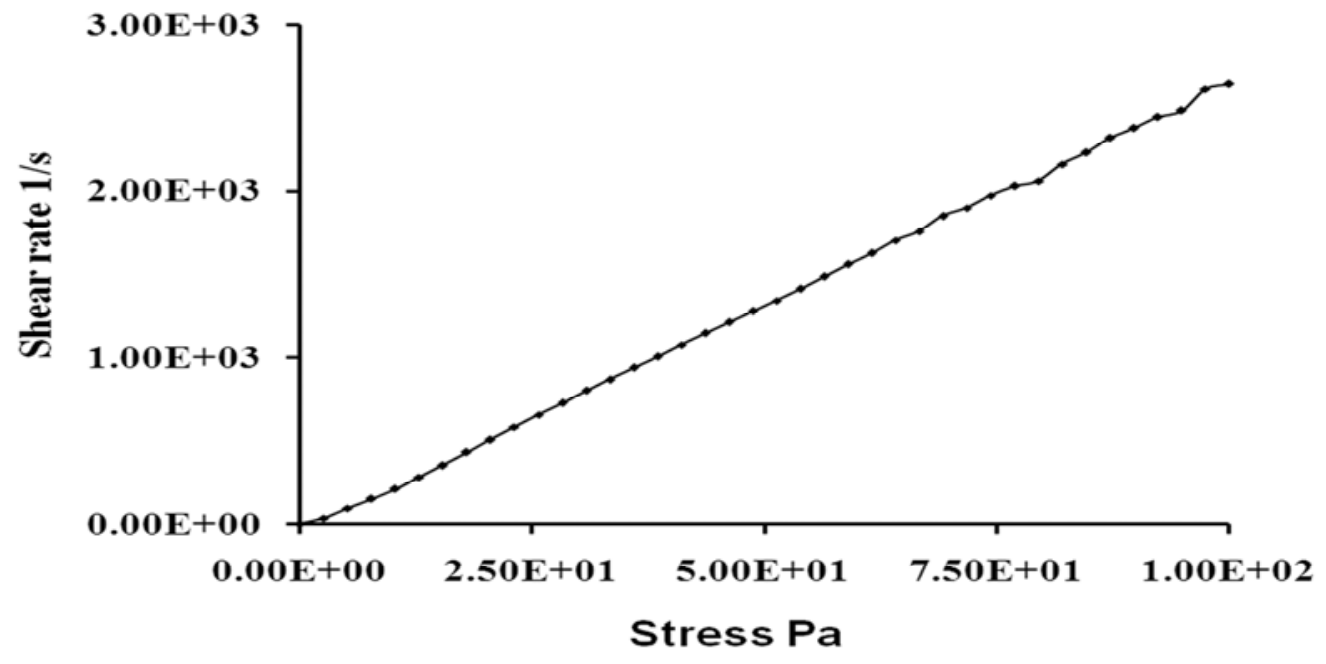

Figure 3. Rheogram of SES presenting correlation between shear stress and shear rate for A- SES 10\%; BSES $30 \%$ and C-SES $50 \%$ 

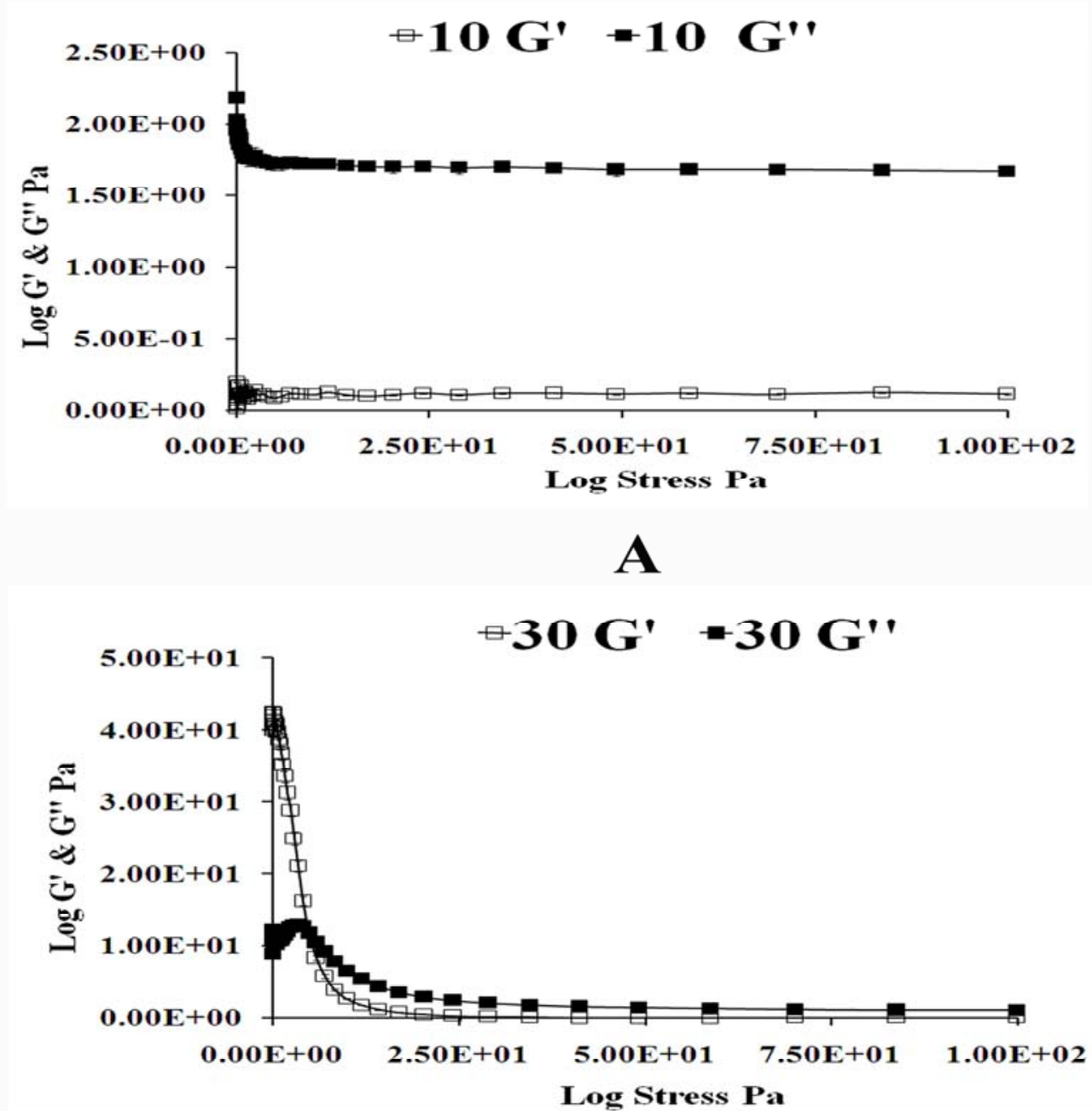

B
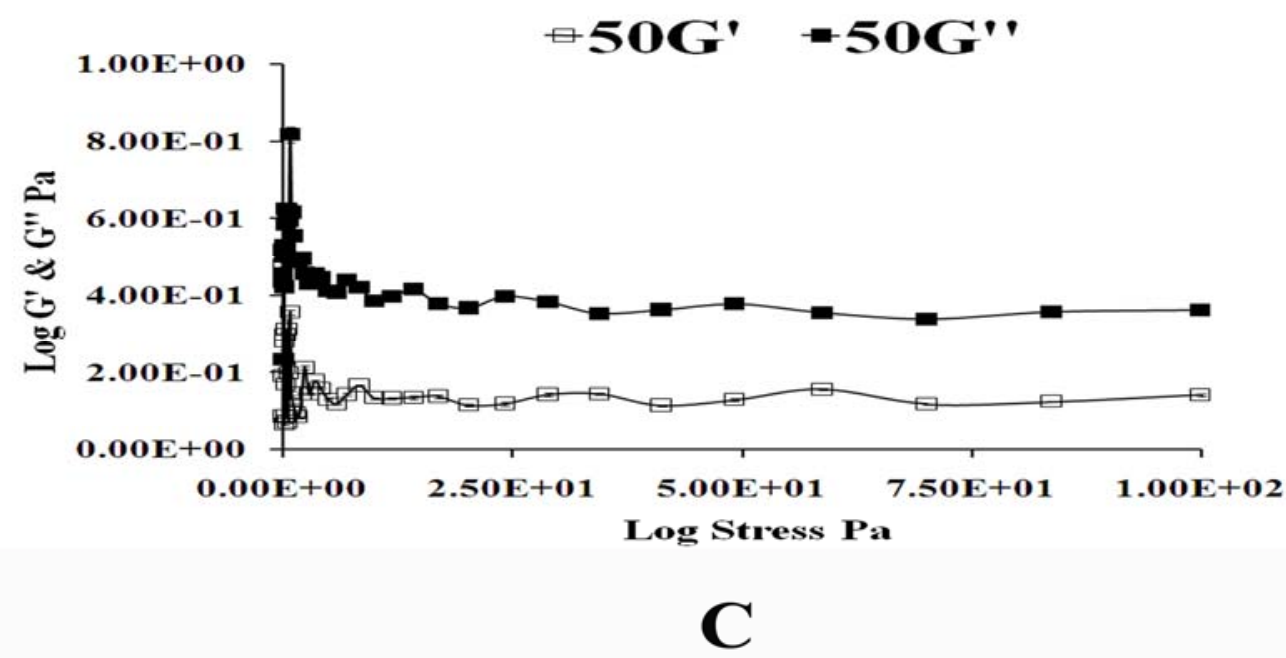

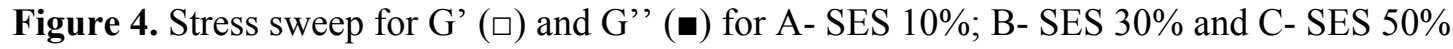



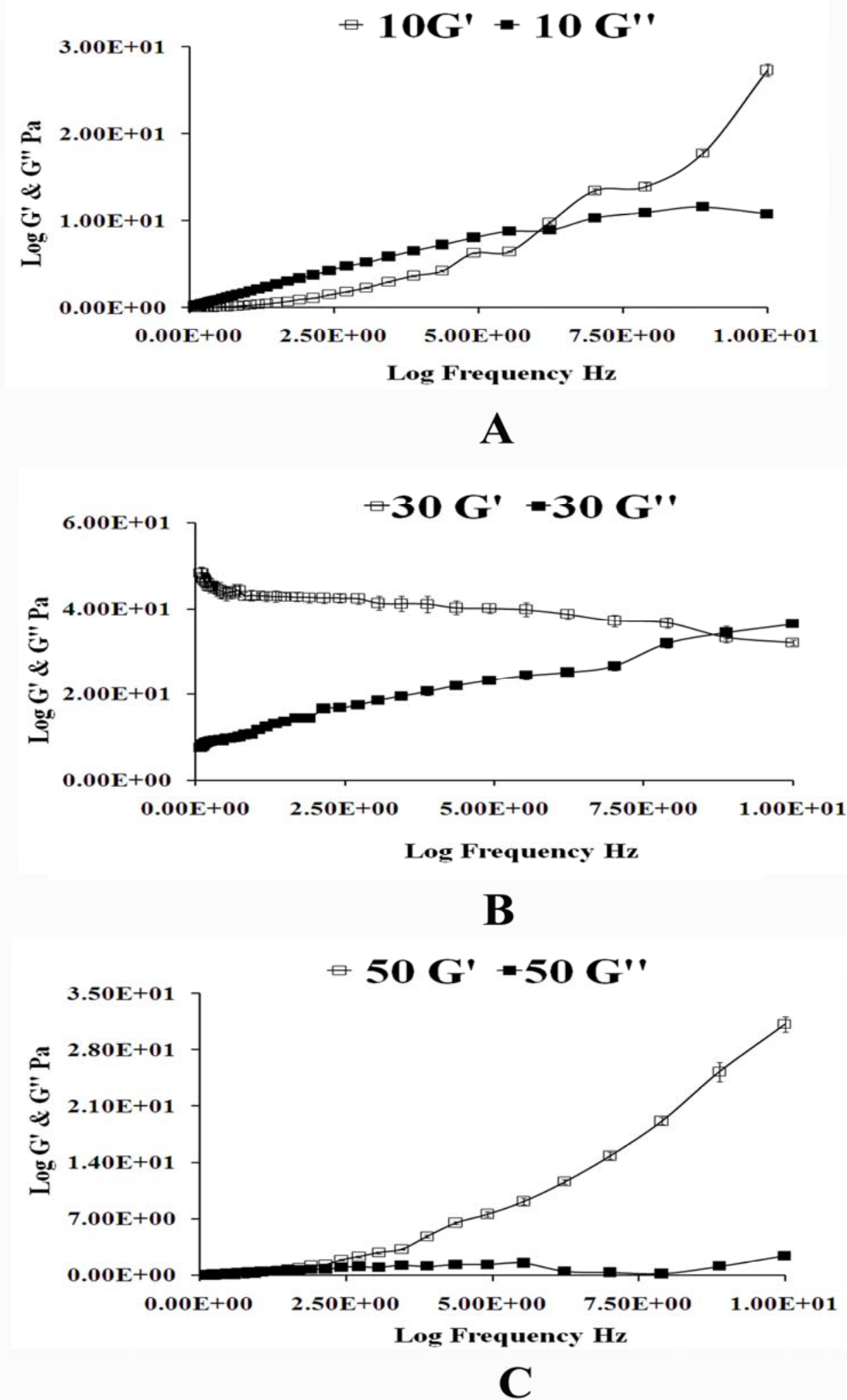

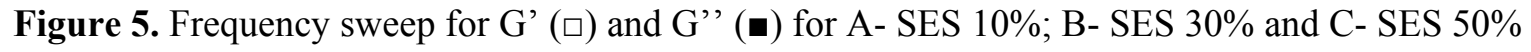




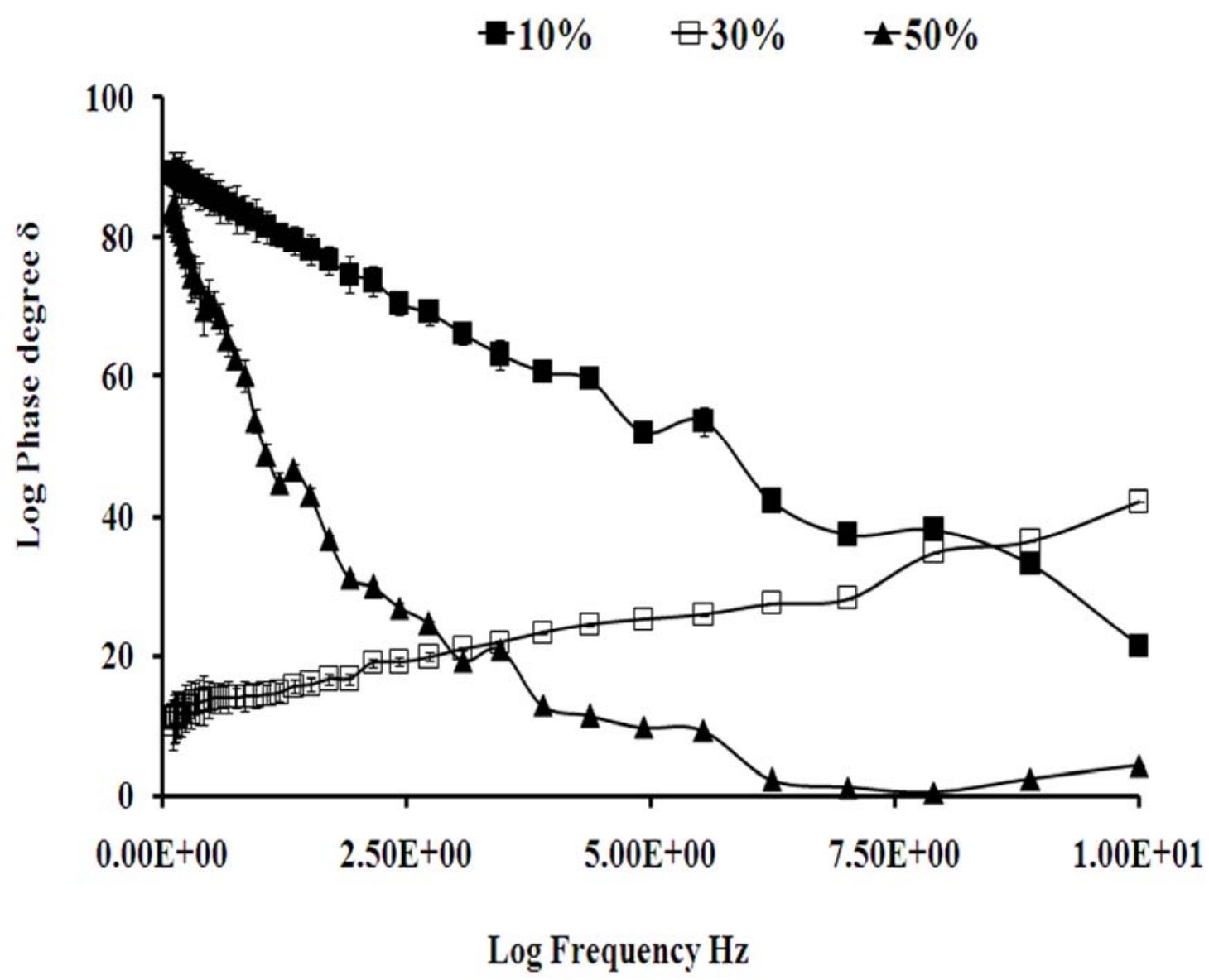

Figure 6. Effect of frequency sweep on phase degree for 10, 30 and 50\% SES

Table 3. Results for first melting transition for free water in DSC thermogram of studied SES

\begin{tabular}{cccccc}
\hline SES \% & Onset $\left({ }^{\circ} \mathbf{C}\right)$ & $\begin{array}{c}\text { Peak } \\
\left({ }^{\circ} \mathbf{C}\right)\end{array}$ & $\begin{array}{c}\text { End } \\
\left({ }^{\circ} \mathbf{C}\right)\end{array}$ & $\begin{array}{c}\text { Heat } \\
\mathbf{J} / \mathbf{g}\end{array}$ & $\begin{array}{c}\text { SBW } \\
\%\end{array}$ \\
\hline 10 & NA & 0 & 0 & 0 & 100 \\
30 & NA & 0 & 0 & 0 & 97.52 \\
50 & -0.55 & 0.36 & 1.38 & -8.26 & 87.1 \\
70 & -2.13 & 0.51 & 1.35 & -42.80 & 74.41 \\
DW & -3.17 & 0.27 & 1.59 & -85.41 & NA \\
\hline
\end{tabular}




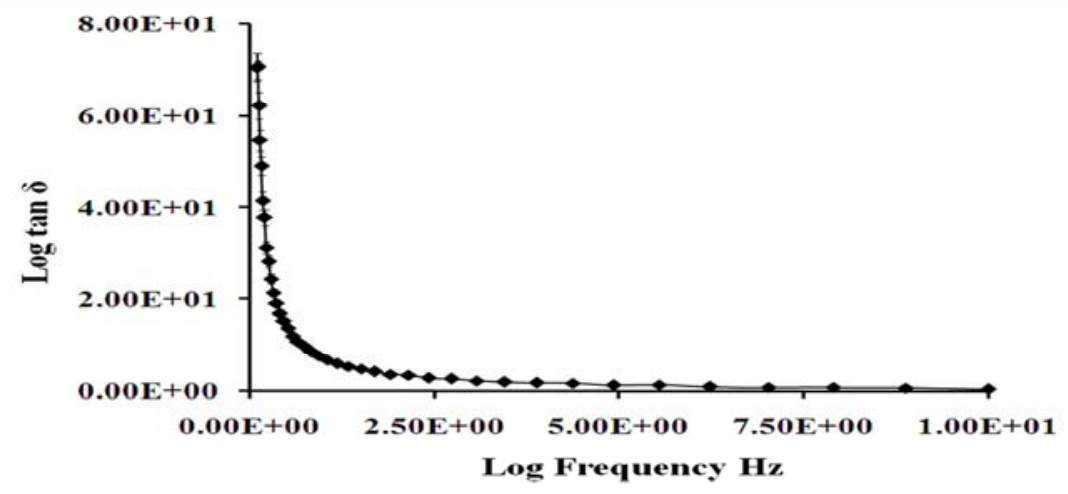

A

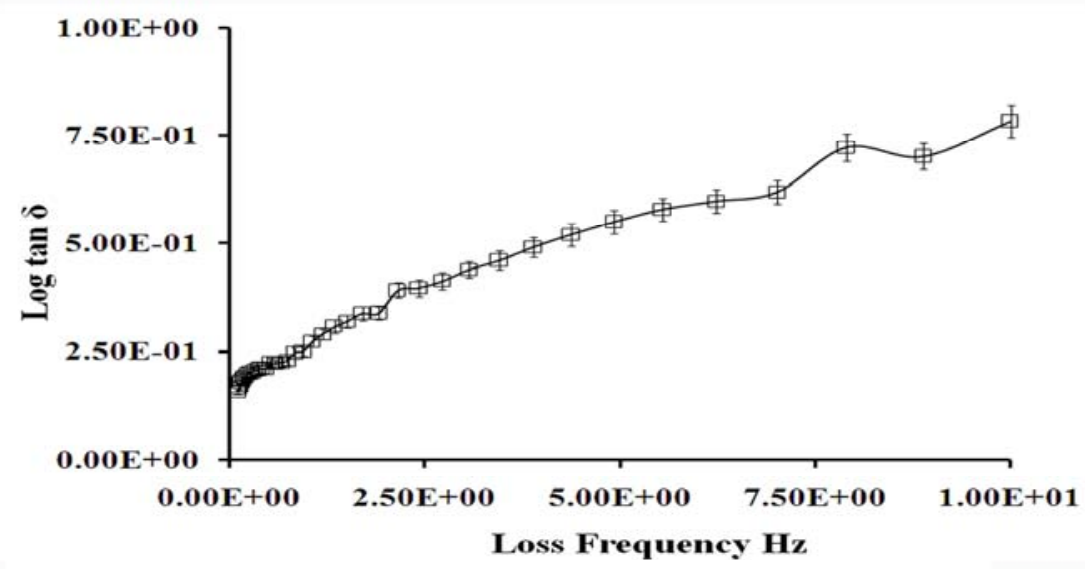

B

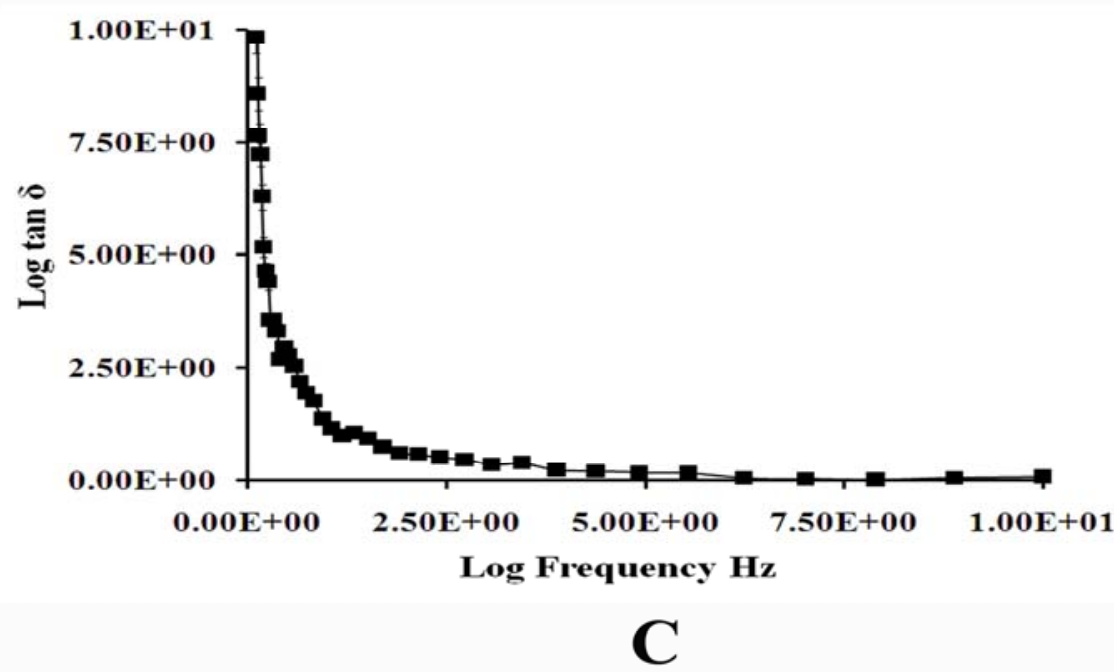

Figure 7. Effect of frequency sweep on loss tangent for A-SES 10\%; B SES 30\% and C- SES 50\% 


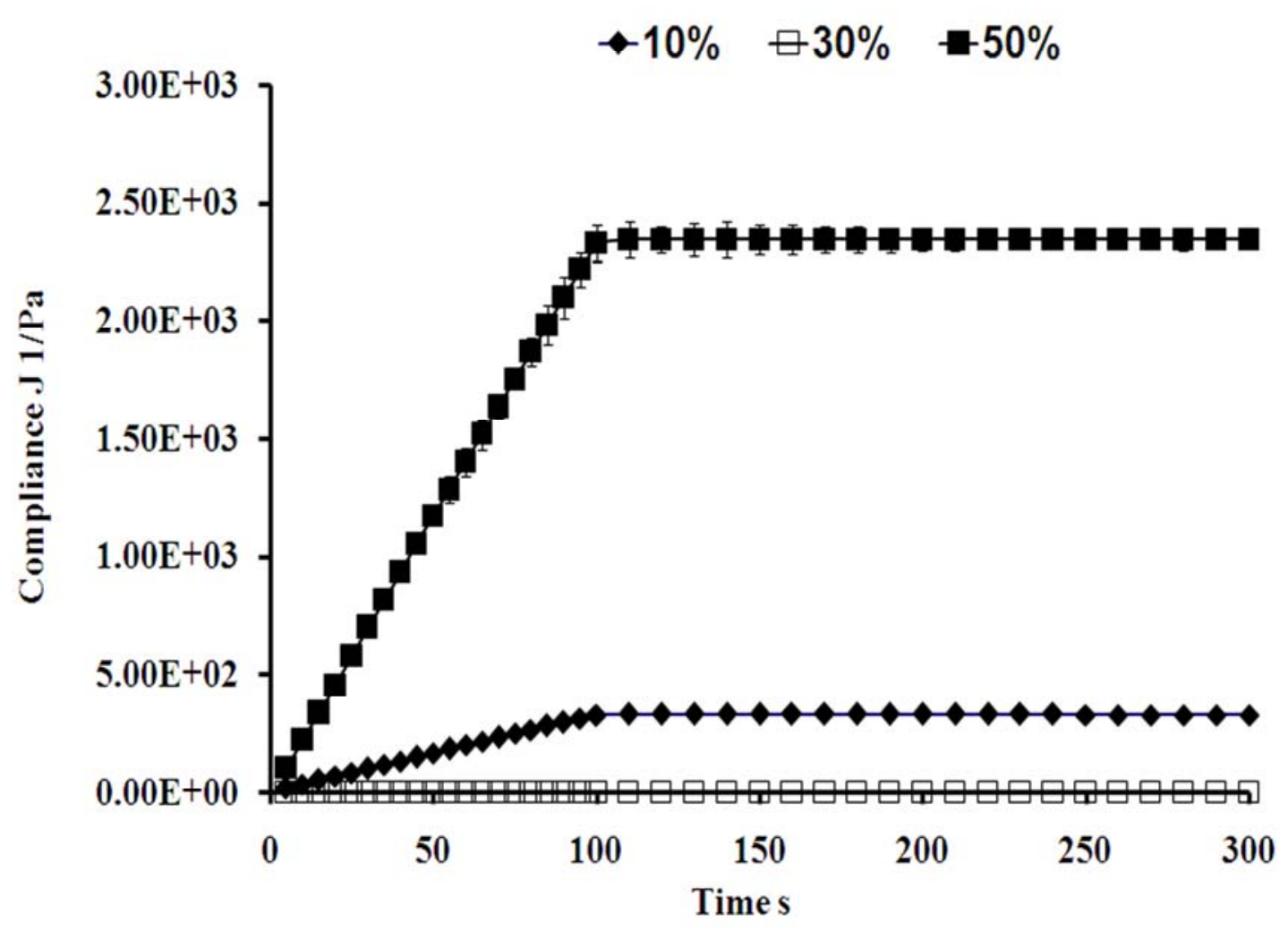

Figure 8. Creep recovery for 10,30 and $50 \%$ SES

Annota et al. (26) clearly indicated that the relationship between shear rate and stress reveals type of LC phase. Direct Newtonian relationship is peculiar of cubic phase, while non-Newtonian relationship is prevalent for lamellar phase. Based on this, lamellar phase was evident in $30 \%$ SES while formation of micellar cubic phase was confirmed in all other SES. Thus, formation of LC phase in studied SES was confirmed by polarizing microscopy, DSC and viscometry.

In oscillation frequency sweep, SES 30\% exhibited exactly opposite trend as compared to other SES. In SES 30\%, G' was higher than G', at lower frequency while at higher frequency, situation was reverse. In all other SES, G' was increased drastically with applied frequency. G' is measure of energy stored and recovered per cycle of deformation and reflects the elastic component of a viscoelastic material. G' is a measure of the energy lost per cycle and reflects the viscous component. If G' dominates over G', the sample is predominantly viscous and tends to be elastic when $G$ ' is higher than G" $(27,28)$. Therefore, it can be summarized that, in SES 30\%, viscous component was predominant while in other SES, elastic component was dominating. Both phase degree and loss tangent were increased for SES 30\% while these rather decreased for other SES. Thus, in SES 30\%, decrease in G', an increase in phase degree and loss tangent with applied frequency indicate transformation from elastic region to viscous region. Hence, it was concluded that, a weak and fragile LC phase structure is present in SES 30\%, which transformed to viscous region with frequency. For other SES, increase in G', decrease in phase degree and loss tangent is an indicative of induction of elastic component or little structural development. During self-emulsification, weak and fragile LC phase structure observed for 30\% SES must have ruptured easily, with no resistance to shear induced deformation and hence, this SES emulsified into nano sized droplets. In case of other SES, induction of elastic component, which might have resulted from intermolecular arrangement 
presented little resistance to shear induced deformation resulting in comparatively larger droplets. Therefore, the difference in selfemulsification performance or observed droplet size was attributed to viscoelastic properties of intermediate LC phase as nature and pattern of rupture of LC phase is totally governed by its viscoelastic properties.

In stress sweep, it was observed that G', was greater than $G^{\prime}$ for 10, 50, 70 and $90 \%$ SES while in frequency sweep, G' was monotonously increased with applied frequency. This was attributed to superiority of frequency sweep over stress sweep to represent the rheological fingerprint of material as prior is performed within rheological ground state of the material (29). For 30\% SES, though similar trend was observed in both stress sweep and frequency sweep, rate of decrease in G' was much higher in stress sweep as compared to frequency sweep.

All hydrated SES were further analyzed for phase characterization using Small angle X-ray diffratcometer (SAXS) and small angle neutron scattering (SANS). Owing to production of very weak signals, it was difficult to interpret the data. Even repeated measurements for longer durations were unfruitful.

\section{CONCLUSION}

This study has focused on the role of viscoelastic properties of intermediate LC phase in selfemulsification performance and proved that observed difference in the droplet size after emulsification is a function of viscoelastic properties of intermediate LC phase. From this study, it was concluded that for efficient or selfnanoemulsification, the intermediate LC phase must be completely viscous or weak and fragile with little or no resistance to shear induced deformation. Thus, rheological investigation of LC phase in SES can serve as one of the tools to investigate mechanism and predict performance of the selfemulsification. The established relationship between viscoelastic properties of intermediate LC phase and self-emulsification performance may be further explored in the design of optimum SES. The rheological characteristics based estimation of performance can be explored further for more complex systems.

\section{ACKNOWLEDGMENT}

Authors are thankful to Sasol GmbH, Germany for gift sample of 1742. Shailesh V. Biradar and Ravindra S. Dhumal are thankful to Council of Industrial and Scientific Research, New Delhi, India for providing financial assistance in form of Senior Research Fellowship. Authors wish to express gratitude towards Dr. P. U. Sastry from Solid State Physics Department, Bhabha Atomic Research Center, Mumbai, India for extending small angle and neutron XRD instrument facilities for analysis of our samples.

\section{REFERENCES}

[1]. Gursoy RN, Benita S. Self-emulsifying drug delivery systems (SEDDS) for improved oral delivery of lipophilic drugs. Biomed Pharmacother, 58: 173-182, 2004.

[2]. Pouton CW. Lipid formulations for oral administration of drugs: non-emulsifying, selfemulsifying and 'self-microemulsifying' drug delivery systems. Eur J Pharm Sci, 11: S93-S98, 2000.

[3]. Gershanik T. Bonita S. Self-dispersion lipid formulations for improving oral absorption of lipophilic drugs. Eur J Pharm Biopharm, 50: 179-188, 2000.

[4]. Lawrence JM, Rees GD. Microemulsion-based media as novel drug delivery systems. Adv Drug Del Rev, 45: 89-121, 2000.

[5]. Reiss H. Entropy-induced dispersion of bulk liquids. J Colloids Interface Sci, 53: 61-70, 1975.

[6]. Constantinides PP. Lipid microemulsions for improving drug dissolution and oral absorption: physical and biopharmaceutical aspects. Pharm Res, 12: 1561-72, 1995.

[7]. Dabros T, Yeung A, Masliyah J, Czarnecki J. Emulsification through area contraction. J Colloids Interface Sci, 210: 222-224, 1999.

[8]. Groves MJ, De Galindez DA. The selfemulsifying action of mixed surfactants in oil. Acta Phar Suec, 13: 361-372, 1976.

[9]. Pouton CW. Formulation of self emulsifying drug delivery system. Adv Drug Del Rev, 25: 47-58, 1997.

[10]. Pouton CW. Self-emulsifying drug delivery systems: assessment of the efficiency of emulsification. Int J Pharm, 27: 335-348, 1985. 
[11]. Rang MJ, Miller CA. Spontaneous emulsification of oils containing hydrocarbon, non-ionic surfactant, and oleyl alcohol. J Colloids Interface Sci, 209: 179-92, 1999.

[12]. Wakerly MG, Pouton CW, Meakin BJ, Morton FS. Self-emulsification of vegetable oil-nonionic surfactant mixtures. ACS Symp Series, 311: 242-55, 1986.

[13]. Craig DQM, Barker, SA, Banning, D, Booth $\mathrm{SW}$. An investigation into the mechanism of self-emulsification using particle size analysis and low frequency dielectric spectroscopy. Int $\mathrm{J}$ Pharm, 114: 103-110, 1995.

[14]. Collaborative International Pesticide Analytical Council (CIPAC), Handbook1, WHO, 1973.

[15]. Rosevear FB. The microscopy of the liquid crystalline neat and middle phases of soaps and synthetic detergents. J Am Oil Chem Soc, 31: 628-639, 1954.

[16]. Ivanova R, Lindman B, Alexandris P. Effect of pharmaceutically acceptable glycols on the stability of the liquid crystalline gels formed by poloxamer 407 in water. J Colloid Interface Sci, 252: 226-235, 2002.

[17]. Lindblom G, Rilfors L. Cubic phases and isotropic structures formed by membrane lipidspossible biological relevance. Biochim Biophys Acta, 988: 221-256, 1989.

[18]. Rodrýguez-Abreu C, Garcýa-Roman M, Kunieda H. Rheology and dynamics of micellar cubic phases and related emulsions. Langmuir, 20: 5235-5240, 2004.

[19]. Efrat R, Aserin A, Kesselman E, Danino D, Wachtel E, Garti N. Liquid micellar discontinuous cubic mesophase from ternary monoolein/ethanol/water mixtures. Colloid Surface A, 299: 133-145, 2007.

[20]. Garti N, Anserin A, Ezrahi S, Tiunova I, Berkovic B. Water behavior in nonionic surfactant systems I: subzero temperature behavior of water in nonionic microemulsions studied by DSC. J Colloid Interface Sci, 178: 60-68, 1996.

[21]. Schulz PC, Puig JE, Barreiro G, Torres LA. Thermal transitions in surfactant-based lyotropic liquid crystals. Thermochi Acta, 231: 239-256, 1994.

[22]. Wesis J, McClements DJ. Influence of ostwald ripening on rheology of oil-in-water emulsions containing electrostatically stabilized droplets. Langmuir, 16: 2145-2150, 2000.

[23]. Korhonen M. Rheological properties of pharmaceutical creams containing sorbitan fatty acid ester surfactants. Academic Dissertation, University of Helsinki, Finland, 2004.

[24]. Tadros T. Application of rheology for assessment and prediction of the long-term physical stability of emulsions. Adv Colloid Interface, 109: 227-258, 2007.

[25]. Santos OD, Rocha-Filho PA. Influence of surfactant on the thermal behavior of marigold oil emulsion with liquid crystal phases. Drug Dev Ind Pharm, 33: 543-549, 2007.

[26]. Antona PD, Parker WO, Zanirato MC, Esposito E, Nastruzzi C. Rheologic and NMR characterization of monoglyceride-based formulations. J Biomed Mater Res, 52: 40-52, 2000 .

[27]. Varma SR, Christy MW. Rheology of microcrystalline cellulose and sodiumcarboxymethyl cellulose hydrogels using a controlled stress rheometer: Part II. Int J Pharm, 292: 63-73, 2005.

[28]. Lippacher A, Muller RH, Mader K. Liquid and semisolid $\mathrm{SLN}^{\mathrm{TM}}$ dispersion for topical application: rheological characterization. Eur J Pharm Biopharm, 58: 561-567, 2004.

[29]. Kobayashi M, Ishikawa S, Samejima M. Application of nonlinear viscoelastic analysis by the oscillation method to some pharmaceutical ointments in the Japanese Pharmacopoeia. Chem Pharm Bull, 30: 44684478, 1982. 